\title{
Comparison of Histidine-Tryptophan-Ketoglutarate and University of Wisconsin Preservation in Renal Transplantation
}

\author{
R. J. Lynch, J. Kubus, R. H. Chenault, \\ S. J. Pelletier, D. A. Campbell \\ and M. J. Englesbe* \\ Department of Surgery, Division of Transplantation, \\ University of Michigan, Ann Arbor, MI \\ * Corresponding author: Michael J. Englesbe, \\ englesbe@umich.edu
}

Histidine-tryptophan-ketoglutarate (HTK) is replacing University of Wisconsin (UW) solution as the preservation fluid for renal allografts in many centers, but recent large-scale data to support this transition are lacking. We conducted a retrospective analysis of patient and graft outcomes after renal transplantation at our center, comparing $\mathbf{4 7 5}$ consecutive living donor and 317 deceased donor transplants since the adoption of HTK with equal numbers of grafts preserved using UW solution. Data collected included donor and recipient age, race, sex, comorbidities and graft ischemia time. Graft and patient survival, as well as the incidence of delayed graft function (DGF), were studied by Kaplan-Meier and Cox regression analysis. No significant difference was seen in either patient or graft survival. Deceased donor kidneys in the HTK group had a higher incidence of DGF than the UW cohort whereas this trend was reversed in the case of living donor organs. In multivariate analysis, HTK was associated with a significant risk reduction on the incidence of DGF. Prolonged preservation with HTK compared to UW was not associated with excess risk to the graft or patient. In summary, HTK demonstrated efficacy similar to UW in terms of patient and graft survival.

Key words: HTK solution, kidney, preservation, preservation solution, preservation solutions, UW preservation solution, UW solution

Received 02 September 2007, revised 14 October 2007 and accepted for publication 24 October 2007

\section{Introduction}

Histidine-tryptophan-ketoglutarate (HTK) solution was introduced in the 1970s as a cardioplegic agent, and was initially described as an allograft storage solution in 1984. In recent years, HTK has replaced University of Wisconsin
(UW) solution as the standard organ preservation fluid at many centers. The purported advantages of HTK include lower viscosity and improved organ flushing characteristics, better cell preservation over a wide range of temperatures and increased clearance of residual donor blood from the microvasculature $(1,2)$. Anecdotal evidence also suggests decreased potential for causing bradyarrhthymias after reperfusion of the renal allograft when compared to $\mathrm{UW}$, though in practice this is a rare and largely preventable occurrence with either solution (3-5). HTK is also considerably less expensive to use than UW, despite the need for higher volumes of fluid per donor recovery (6).

Although HTK is now widely used, many continue to question its suitability as a kidney preservation agent. Cell culture and small animal models have shown unfavorable changes in cell morphology, caspase activation and other markers of tissue injury in HTK-preserved samples $(7,8)$. Clinical studies have not demonstrated significant differences between HTK and UW in deceased donor kidneys $(9,10)$, but recent, large-scale data with follow-up of both deceased donor and living-donor grafts are lacking. Outcomes from organs with prolonged ischemic time are of particular interest, as it is in these cases that HTK is posited to provide suboptimal preservation (11).

Our center adopted HTK for living donor transplants in 2002, and for deceased donor transplants beginning in 2003. In this report, we present data from our center regarding 475 living and 317 deceased donor organs preserved with HTK. We compared patient and graft survival rates from these operations with those of the latest UWpreserved grafts at our center, dating back to 1997. We also studied rates of technical graft loss and delayed graft function, as well as outcomes with organs that underwent prolonged cold ischemia. Our hypothesis was that preservation with HTK and the UW solution would be comparable for both deceased and living donor kidney transplants.

\section{Methods}

\section{Patients}

Approval for data collection and analysis was obtained from the University of Michigan Institutional Review Board. All living donor renal allografts at the University of Michigan were preserved with HTK solution beginning in October 2002, and all deceased donor kidneys recovered within Region 


\section{Lynch et al.}

10 were preserved with HTK solution beginning in December 2003. All adult kidney-only transplant procedures utilizing HTK were retrospectively reviewed, totaling 475 living and 317 deceased donor organs. Historical controls were obtained by using equal numbers of the most recent adult patients who received kidney transplants that had been preserved using UW solution, dating back to 1997 for living donors and 1999 for deceased donors. Data were obtained from the University of Michigan online transplant information database and patient care systems, including recipient age, gender, race, underlying cause of renal failure, transplant date, cold and warm ischemia time, lost to follow-up date, date of death, date of graft loss and ALL Patient Refined Diagnosis-Related Group (APR-DRG) severity score. The APR-DRG is a measure of complexity of care for given conditions, and can be used to convey severity of illness and risk of mortality across a diagnosis group. In common practice, APR-DRG weights reflect the amount of resources required to care for patients with the same disease or operation. Delayed graft function was defined as requirement for dialysis in the first 7 days after transplant. Donor characteristics included age, gender and donor type.

\section{Statistical analysis}

The student's $t$-test was utilized to compare continuous variables, and the chi-square test used to determine differences in categorical variables. The primary outcome measures included time-dependent patient and graft survival. The primary exposure variable was the type of preservation solution (HTK solution vs. UW.) Patient and graft survival were compared using Kaplan-Meier survival analysis, stratifying for living donors and deceased donors. Cox proportional regression models were created to determine independent covariates (donor, recipient and preservation) that affected patient and graft survival. This method also allowed evaluation of interaction effects between the preservative type, cold-ischemia time and donor type. Rates of technical graft loss, defined as graft loss within 2 weeks of the kidney transplant operation without evidence of rejection, were computed for each fluid and donor type. SPSS V15.0 (Chicago, IL) was used for data analysis.

\section{Results}

Demographic data on living and deceased donor organs are summarized in Table 1. Among the deceased donor recipients, the HTK group had a higher percentage of African Americans than did the UW patients. Kidneys preserved with HTK were recovered from significantly older donors and transplanted into older recipients when compared to the UW control group. Similarly, among the living donor recipients, in comparison to the UW-preserved group, the HTK group of living-donor organ recipients was older and had a higher proportion of males. In addition, cold ischemia time in the HTK recipients was longer (117 vs. $87.3 \mathrm{~min}$, $p<0.01$ ). APRDRG weight was comparable between the living donor groups. Finally, the deceased donor HTK recipients' APRDRG weight tended toward the higher end of the scale than that of the UW sample (Figure 1).

Kaplan-Meier analysis demonstrated no difference in patient survival between HTK and UW preservation solutions, in either the living-donor or deceased donor groups (Figure 2). Patient survival at 50 months was over $80 \%$ in the deceased donor patients and over $90 \%$ in the livingdonor patients. Graft survival did not significantly differ by preservation solution, but in living-donor patients; HTK showed a trend toward improved long-term graft survival over UW solution (Figure 3). Cox regression modeling demonstrated patient survival to be independently predicted by a younger recipient age at transplantation, the absence of diabetes and receiving a living donor compared to a deceased donor kidney (Table 2, part A). Our baseline

Table 1: Recipient and donor demographics

\begin{tabular}{|c|c|c|c|}
\hline \multirow{2}{*}{$\begin{array}{l}\text { Deceased donors } \\
\text { Variable }\end{array}$} & \multicolumn{2}{|c|}{ Preservative } & \multirow[b]{2}{*}{ p-Value } \\
\hline & UW (n=317) & HTK $(n=317)$ & \\
\hline Male sex & $57 \%$ & $62 \%$ & 0.13 \\
\hline Caucasian & $77 \%$ & $67 \%$ & $<0.01^{*}$ \\
\hline Diabetes & $29 \%$ & $36 \%$ & 0.08 \\
\hline Age at transplant (yrs) & $48.6 \pm 13.0$ & $50.8 \pm 12.2$ & $0.02 *$ \\
\hline Donor age (yrs) & $35.0 \pm 15.7$ & $38.0 \pm 15.3$ & $0.02^{*}$ \\
\hline Cold ischemia time (min) & $949.6 \pm 423.2$ & $877.0 \pm 541.4$ & 0.08 \\
\hline Total ischemia time (min) & $991.4 \pm 421.2$ & $912.5 \pm 540.6 .2$ & 0.06 \\
\hline Total ischemia time $>24 \mathrm{~h}$ & $10.6 \%$ & $9.5 \%$ & 0.60 \\
\hline APRDRG weight & $5.8 \pm 1.3$ & $6.1 \pm 1.8$ & $0.048^{*}$ \\
\hline \multirow{2}{*}{$\begin{array}{l}\text { Living donors } \\
\text { Variable }\end{array}$} & \multicolumn{2}{|c|}{ Preservative } & \\
\hline & UW $(n=475)$ & HTK $(n=475)$ & p-Value \\
\hline Male sex & $54 \%$ & $62 \%$ & $0.01 *$ \\
\hline Caucasian & $84 \%$ & $83 \%$ & 0.36 \\
\hline Diabetes & $33 \%$ & $33 \%$ & 0.53 \\
\hline Age at transplant (yrs) & $43.8 \pm 13.4$ & $47.8 \pm 13.4$ & $<0.01^{*}$ \\
\hline Donor age (yrs) & $39.9 \pm 11.4$ & $40.4 \pm 10.7$ & 0.43 \\
\hline Cold ischemia time (min) & $87.3 \pm 68.0$ & $117.8 \pm 118.7$ & $<0.01^{*}$ \\
\hline Total ischemia time (min) & $120.2 \pm 69.8$ & $152.1 \pm 119.5$ & 0.31 \\
\hline Total ischemia time $>24 \mathrm{~h}$ & $0.0 \%$ & $0.1 \%$ & 0.47 \\
\hline APRDRG weight & $5.4 \pm 0.90$ & $5.5 \pm 0.93$ & 0.36 \\
\hline
\end{tabular}

$* P<0.05$. 
Figure 1: Distribution of APRDRG severity scores (composite index of comorbidities and acute illness severity) among recipients of living and deceased donor kidney allografts, by preservative solution type.

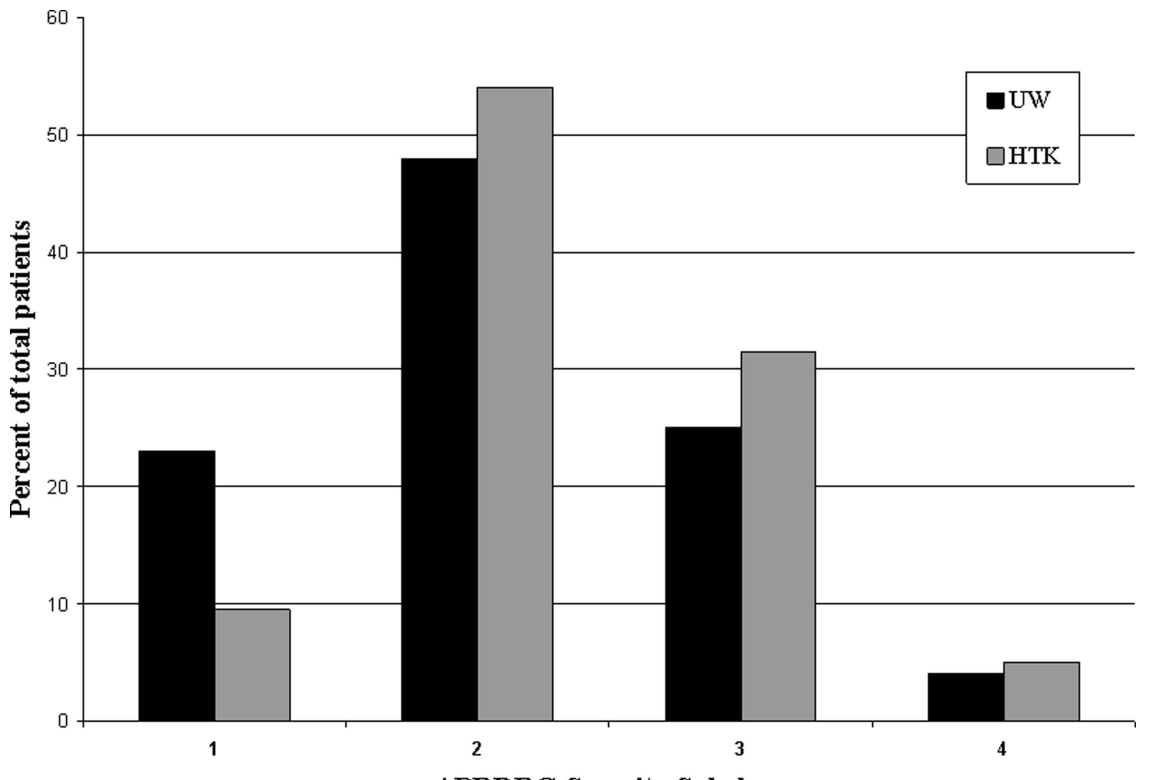

APRDRG Severity Subclass case was a female Caucasian without diabetes who received a kidney from a living donor preserved with UW solution with a cold ischemia time of less than $24 \mathrm{~h}$. This model noted no independent relationship between preservation solution and patient survival. Organs with a cold ischemia time of more than $24 \mathrm{~h}$ did not significantly impact survival. Interaction modeling to assess the cumulative impact of choice of preservative fluid with allograft type and prolonged ischemia time did not demonstrate a significant effect on patient survival. In a model limited to recipients of living donor grafts, advanced recipient age and diabetes imparted a significant risk of death, but preservation fluid did not affect survival (Table 2, part B). The deceased donor model was most heavily impacted by recipient age, with additional dependence on donor age. Again, preservation fluid did not reach statistical significance for patient survival.

Graft survival was defined as independence from dialysis, or by loss of function in grafts of patients not yet requiring dialysis. Modeling by Cox regression showed a 45\% higher risk of graft loss with deceased donor than with living donor kidneys (Table 3, part A). Delayed graft function imparted a large and statistically significant risk to long-term graft survival. Use of UW or HTK did not change risk of graft loss, nor did prolonged cold-ischemia time. Interaction variables combining preservation fluid, extended cold-ischemia, and donor type were not significant predictors of graft loss, and analyses were of insufficient power to include in the model. Discrete analysis of deceased donors showed an increased risk with organs from older donors, while none of the variables in a living-donor model reached statistical significance (Table 3, part B).
Analysis of rates of technical graft loss was limited by its low overall incidence of $0.44 \%$. Cox modeling did not isolate predictive factors for organ loss within 14 days of transplantation, and rates in the UW and HTK groups were comparable across donor type (Table 4). Data on delayed graft function are also shown in Table 4. Deceased donor kidneys in the HTK group had a higher incidence of DGF that those in the UW cohort, whereas this trend was reversed in the case of living donor organs. In multivariate analysis, HTK organ preservation was associated with a $70 \%$ reduction in risk for DGF, as shown in Table 5. Other significant factors in the DGF model included race other than Caucasian, advanced donor age, deceased donor graft and recipient diabetes. Cold ischemia time did not reach significance in this model, and interaction variables were of insufficient power to model reliably because of small sample size. The total number of deceased donor recipients with DGF after prolonged ( $>24 \mathrm{~h}$ ) ischemia was numerically similar between UW and HTK, with 9 patients in each group having DGF and 25 and 24 patients having no DGF under UW and HTK, respectively $(p=N S)$.

\section{Discussion}

In this study, we conducted a retrospective analysis of graft and patient survival in recipients of renal allografts preserved with either UW or HTK solution. Our data do not show any statistically significant difference between the two preservation fluids, though there was a trend toward improved graft survival in the HTK living donor group. We also studied whether choice of preservation fluid affected rates of technical graft loss, and again found no significant 
Living donor

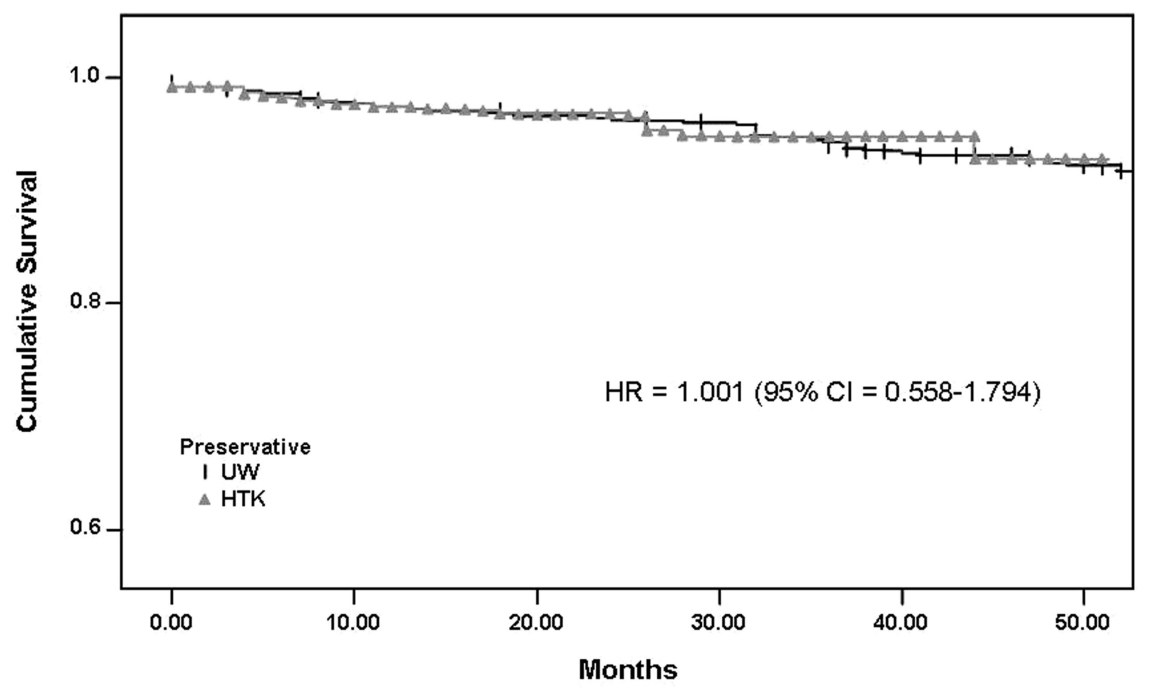

Deceased donor

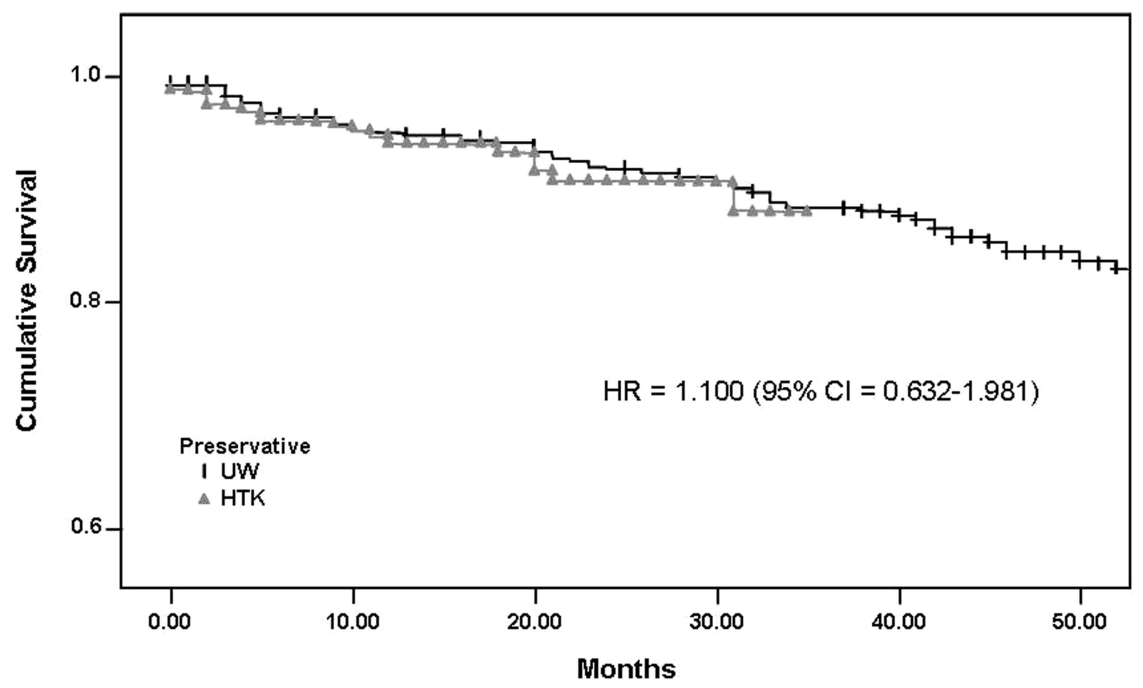

Figure 2: Kaplan-Meier patient survival after kidney transplant using either UW or HTK organ preservation solution. The hazard ratio refers to the risk of patient death when HTK solution was used compared to UW solution. differences attributable to graft storage solution. We did note differences in DGF rates; the HTK cohort had a higher incidence of DGF in deceased donor cases and a lower incidence of DGF in living donor cases. In spite of these differences in DGF rates, overall patient and graft survival rates were comparable. Although there are limitations to this analysis, our results suggest that there are no significant short- or long-term clinically significant differences between UW solution and HTK in deceased donor and living kidney transplantation.

Previous comparisons between UW and HTK in renal transplantation have been limited by small sample size and relatively short follow-up (10-12). The largest studies, from Eurotransplant, took place in the early 1990s. In addition, the great majority of papers relating to UW and HTK in renal transplantation included only deceased donor organs
(9-13). Given the widespread use of HTK solution for organ preservation in United States, important questions remain regarding the use of HTK in living donor transplantation and the implications of using HTK in cases of prolonged cold ischemia times. In addition, no previous studies have compared University Wisconsin solution and HTK solution with respect to long-term graft function. Our data suggest that the use of HTK solution for the preservation of both living and deceased donor kidneys has a similar efficacy when compared to UW. There was a numerically higher graft survival for living donor kidneys preserved with HTK when compared to UW, but this did not reach statistical significance.

Within our organ procurement organization, the standard donor operation includes a $5 \mathrm{~L}$ aortic flush with HTK, with an additional $300 \mathrm{cc}$ of HTK used for back-table perfusion. 


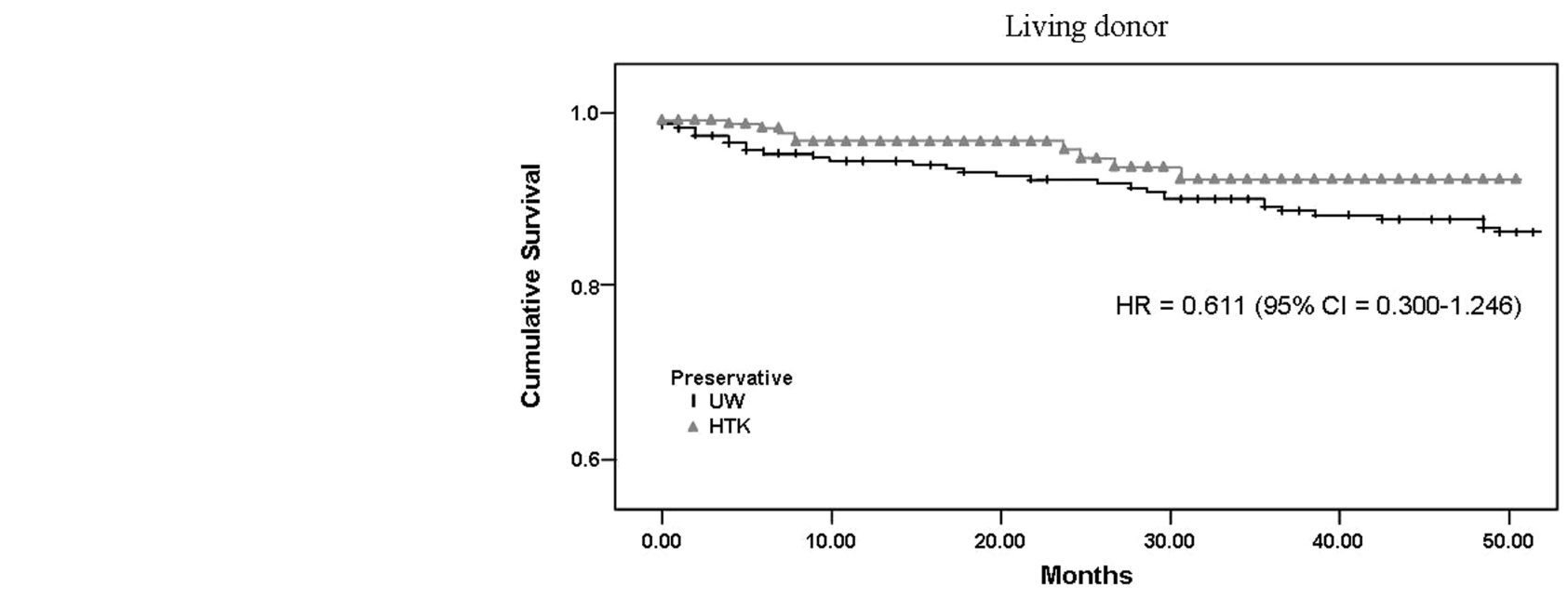

Figure 3: Kaplan-Meier kidney allograft survival after transplant using either UW or HTK organ preservation solution. The hazard ratio refers to the risk of graft loss when HTK solution was used compared to UW solution.

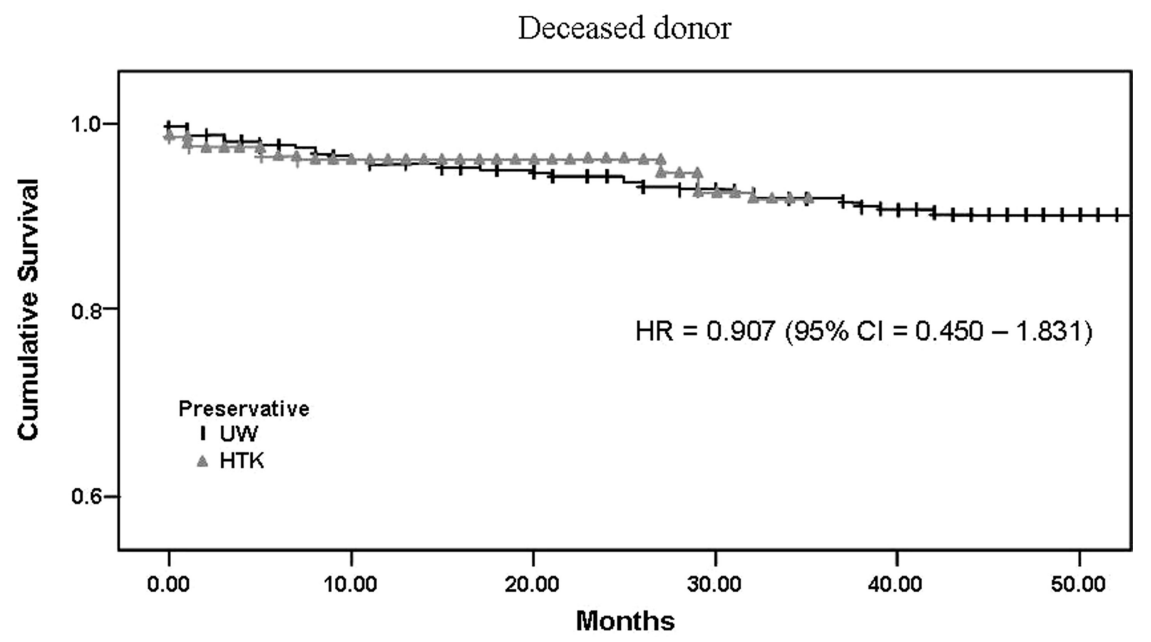

This is concordant with data reported from European studies, where 5-6 L was the average HTK perfusate volume $(9,14)$, but greater than in the Agarwal series, which used an average flush of $3.4 \mathrm{~L}$ (12). It is notable that the manufacturer's instructions for HTK initially involved a $10 \mathrm{~L}$ flush, but now recommend 6-8 min of perfusion with no specific volume advisory (15). To date, no data have been published correlating outcome with flush volumes beyond titration to clear effluent.

Our experience suggests that, with cold ischemic times over $24 \mathrm{~h}$, there is no detriment associated with HTK use. This claim has been perhaps the most contentious in the adoption of HTK over UW solution. Roels et al. found an increase in delayed graft function from $18 \%$ to $24 \%$ with UW, and from $26 \%$ to $50 \%$ with HTK, with ischemia times $>24 \mathrm{~h}$ (11). In contrast, later work by Agarwal et al. showed a reduction from $56 \%$ DGF with UW to $16 \%$ with HTK (12). These studies offered similarly conflicting results regarding graft function at 12 to 18 months posttransplantation. Donor and recipient demographics were comparable in all three studies, but the Roels study, like our own, involved recipient operations at one center, as opposed to following outcomes for grafts transplanted at multiple centers. Our graft survival rates are consistent with recent studies, and suggest equivalence between the two preservation solutions in the setting of prolonged ischemia $(16,17)$. Our data on delayed graft function are mixed. Despite a numerically higher incidence of DGF in the HTK group, Cox multivariable regression analysis shows a reduction in DGF with HTK preservation. This may reflect an era effect, as discussed below, where the HTK variable represents not only preservation solution, but a reference to year of operation.

The primary limitations of our analysis are its retrospective design and the asynchronous nature of the UW and HTK treatment groups. Perioperative and postoperative care of transplant patients is dynamic, and it is not possible to discount an era effect that may mask inequality between preservation fluids. While this cannot be fully excluded as a confounder, certain aspects of the data tend to make it less likely. Table 1 shows that patients in the HTK groups were older and tended toward a higher donor age, recipient 


\section{Lynch et al.}

Table 2: A Cox regression analysis of patient survival following kidney transplantation at the University of Michigan

\begin{tabular}{|c|c|c|c|}
\hline Effect & Hazard ratio & $95 \% \mathrm{Cl}$ & p-Value \\
\hline \multicolumn{4}{|c|}{ A. Overall predictors of patient mortality } \\
\hline Recipient age (risk per year) & 1.042 & $1.028-1.057$ & $<0.001^{*}$ \\
\hline Deceased donor graft & 1.808 & $1.197-2.724$ & $0.005 *$ \\
\hline Diabetes & 1.517 & $1.089-2.113$ & $0.014 *$ \\
\hline Donor age (risk per year) & 1.011 & $0.998-1.024$ & 0.094 \\
\hline HTK organ preservation & 1.416 & $0.765-2.618$ & 0.268 \\
\hline Male sex & 1.148 & $0.818-0.612$ & 0.424 \\
\hline Delayed graft function & 1.398 & $0.603-3.240$ & 0.435 \\
\hline Non-Caucasian race & 0.859 & $0.545-1.354$ & 0.513 \\
\hline Cold ischemia time $>24 \mathrm{~h}$ & 1.115 & $0.436-2.849$ & 0.821 \\
\hline $\begin{array}{l}\text { Combination of (deceased } \\
\text { donor) and (HTK } \\
\text { solution) }\end{array}$ & 1.751 & $0.759-4.048$ & 0.189 \\
\hline $\begin{array}{l}\text { Combination of (Cold } \\
\text { ischemia }>24 \mathrm{~h} \text { ) and } \\
\text { (HTK solution) }\end{array}$ & 1.908 & $0.206-17.54$ & 0.569 \\
\hline \multicolumn{4}{|c|}{$\begin{array}{l}\text { B. Significant predictors of patient mortality, by donor type } \\
\text { Living donors }\end{array}$} \\
\hline $\begin{array}{l}\text { Recipient age (risk per } \\
\text { year) }\end{array}$ & 1.035 & $1.017-1.053$ & $<0.001^{*}$ \\
\hline Diabetes & 1.810 & $1.162-2.820$ & $<0.001 *$ \\
\hline HTK organ preservation & 0.906 & $0.501-1.637$ & 0.744 \\
\hline \multicolumn{4}{|l|}{ Deceased donors } \\
\hline $\begin{array}{l}\text { Recipient age (risk per } \\
\text { year) }\end{array}$ & 1.061 & $1.038-1.085$ & $<0.001^{*}$ \\
\hline Donor age (risk per year) & 1.018 & $1.002-1.035$ & $0.029 *$ \\
\hline HTK organ preservation & 1.054 & $0.558-1.991$ & 0.870 \\
\hline
\end{tabular}

APR-DRG and prevalence of recipient diabetes. With outcomes that indicate clinical equivalence between HTK and UW, it would require a very large era effect related to unmeasured patient care improvements to balance out increased patient risk factors, and to mask a detriment associated with HTK use. Strategies of postoperative immunosuppression and monitoring at the University of

Table 3: Graft survival following kidney transplantation at the University of Michigan: A Cox regression of graft survival

\begin{tabular}{lrrr}
\hline Effect & Hazard ratio & $95 \% \mathrm{Cl}$ & $\mathrm{p}$-Value \\
\hline A. Overall predictors of graft loss & & & \\
Delayed graft function & 3.736 & $1.783-7.829$ & $<0.001^{*}$ \\
Diabetes & 1.550 & $1.008-2.384$ & $0.046^{*}$ \\
Deceased donor graft & 1.453 & $0.854-2.469$ & 0.167 \\
Donor age (risk per year) & 1.009 & $0.993-1.025$ & 0.259 \\
Male sex & 0.895 & $0.587-1.365$ & 0.607 \\
Non-Caucasian race & 1.139 & $0.671-1.933$ & 0.630 \\
Cold ischemia time $>24 \mathrm{~h}$ & 1.298 & $0.385-4.374$ & 0.674 \\
HTK organ preservation & 1.048 & $0.468-2.349$ & 0.909 \\
Recipient age (risk per year) & 1.000 & $0.984-1.017$ & 0.990 \\
B. Independent predictors of graft loss, by & donor type & \\
Living donors & & & \\
$\quad$ HTK organ preservation & 0.700 & $0.445-1.102$ & 0.124 \\
Deceased donors & & & \\
$\quad$ Donor age (risk per year) & 1.030 & $1.007-1.052$ & $0.009^{*}$ \\
HTK organ preservation & 0.792 & $0.484-1.298$ & 0.355 \\
\hline
\end{tabular}

Table 4: Delayed graft function and technical graft failure in renal allografts

\begin{tabular}{|c|c|c|c|}
\hline \multirow[b]{2}{*}{ Effect } & \multicolumn{2}{|c|}{ Preservative } & \multirow[b]{2}{*}{$\mathrm{p}$-Value } \\
\hline & UW $(n=317)$ & $\operatorname{HTK}(n=317)$ & \\
\hline \multicolumn{4}{|l|}{ Deceased donors } \\
\hline Delayed graft function & $17.4 \%$ & $26.2 \%$ & $0.005^{*}$ \\
\hline \multirow{2}{*}{ Technical graft failure } & $0 \%$ & $0.9 \%$ & 0.249 \\
\hline & \multicolumn{2}{|c|}{ Preservative } & \\
\hline Effect & UW $(n=475)$ & $\operatorname{HTK}(n=475)$ & p-Value \\
\hline \multicolumn{4}{|l|}{ Living Donors } \\
\hline Delayed graft function & $8.2 \%$ & $3.2 \%$ & $0.001^{*}$ \\
\hline Technical graft failure & $0.6 \%$ & $0.2 \%$ & 0.624 \\
\hline
\end{tabular}

Michigan have largely stayed the same between 2003 and 2007, and so no such large effect is likely to exist. One area where interpretation of the data is limited is with regard to delayed graft function. In our series, the incidence of DGF increased in the HTK group, but HTK use was independently associated with a reduction in DGF risk.

A reasonable conclusion from our data is that while HTK and UW may perform differently in cellular and small animal models, they appear to be equivalent in terms of preserving renal parenchyma in clinical transplantation. If any clinically important effect were to exist, it might be most evident in the immediate postoperative period or in patients with prolonged cold ischemia. While our data show a higher rate of delayed graft function in the HTK deceased donor, but not living donor population, multivariate regression analysis demonstrates a large and statistically significant advantage to HTK over UW solution. Similarly, no difference was found on regression analysis of graft survival based on preservation fluid and cold ischemia time of more than $24 \mathrm{~h}$. The data set is sensitive to donor factors such as donor age, donor type and prolonged ischemia, as well as to recipient age and diabetes, which have been previously shown to predict technical graft loss (18).

In this report, we present data from our center that supports use of HTK as a graft preservation solution in renal transplantation. Within the limits of retrospective analysis with a historic control, HTK demonstrated efficacy similar to UW in terms of patient and graft survival, and its lower

Table 5: A Cox regression analysis of delayed graft function in renal transplant recipients at the University of Michigan

\begin{tabular}{lccc}
\hline Effect & Hazard ratio & $95 \% \mathrm{Cl}$ & $\mathrm{p}$-Value \\
\hline HTK organ preservation & 0.295 & $0.143-0.607$ & $0.001^{*}$ \\
Non-Caucasian race & 1.917 & $1.281-2.867$ & $0.002^{*}$ \\
Donor age (risk per year) & 1.020 & $1.006-1.033$ & $0.003^{*}$ \\
Deceased donor graft & 2.232 & $1.219-4.086$ & $0.009^{*}$ \\
Diabetes & 1.589 & $1.090-2.315$ & $0.016^{*}$ \\
Cold ischemia time $>24 \mathrm{~h}$ & 1.811 & $0.733-4.476$ & 0.198 \\
Recipient age (risk per year) & 1.006 & $0.991-1.021$ & 0.437 \\
Male sex & 0.871 & $0.602-1.261$ & 0.464 \\
\hline
\end{tabular}


cost represents a financial advantage to our organ procurement organization and our transplant center.

\section{Acknowledgments}

Darrell A. Campbell is supported in part by a grant from Blue Cross and Blue Shield of Michigan. Michael J. Englesbe is supported in part by a grant from the American Surgical Association.

\section{References}

1. Aminalai A, Kehrer G, Grossmann F, Richter J, Bretschneider HJ. Morphological investigation of the porcine liver directly following preservation with Euro-Collins, University of Wisconsin and Bretschneider's HTK solution. Langenbecks Arch Chir 1992; 377: 81-88.

2. Muhlbacher F, Langer F, Mittermayer $C$. Preservation solutions for transplantation. Transplant Proc 1998; 31: 2069-2070.

3. Prien TH, Dietl KH, Zander J, Hachenberg T, Buchholz B. Bradyarrhythmia with University of Wisconsin preservation solution. Lancet 1989; 8650: 1319-1320.

4. Vanrenterghem Y, Roels L, Vandermeersch E, Christiaens R, Gruwez J, Michielsen P. University of Wisconsin preservation solute and bradyarrhythmia. Lancet 1989; 8665: 745.

5. Panzner R, Wollert HG, Hermann M, Taha M, Schischka F. Reperfusion arrhythmias after cardioplegia using Bretschneider-HTK solution. Thorac Cardiovasc Surg 1990; 38: 370

6. Englesbe MJ, Heidt D, Sung R, Pietroski R. Does using HTK soIution for cold perfusion of cadaveric kidneys save money? Transplantation 2006; 82: 580-581.

7. Schmitz V, Klawitter J, Bendrick-Peart J et al. Impact of organ preservation using HTK for graft flush and subsequent storage in UW in rat kidney transplantation. Eur Surg Res 2006; 38: 388-398.

8. Semmelmann A, Neeff H, Sommer O, Thomusch O, Hopt UT, von Dobschuetz E. Evaluation of preservation solutions by ESR- spectroscopy: Superior effects of University of Wisconsin over Histidine-Tryptophan-Ketoglutarate in reducing renal reactive oxygen species. Kidney Int 2007; 71: 875-881.

9. de Boer J, De Meester J, Smits JMA et al. Eurotransplant randomized multicenter kidney graft preservation study comparing HTK with UW and Euro-Collins. Transplant Int 1999; 12 447-453.

10. Hrabalova $M$, Bachleda $P$, Lubuska $L$ et al. Effect of various protective solutions on function after kidney transplantation. Biomed Papers 2003; 147: 197-202.

11. Roels L, Coosemans W, Donck J et al. Inferior outcome of cadaveric kidneys preserved for more than $24 \mathrm{hr}$ in histidine-tryptophanketoglutarate solution. Transplantation 1998; 66: 1660-1664.

12. Agarwal A, Murdock P, Fridell JA. Comprarison of histidinetryptophan-ketoglutarate solution and University of Wisconsin solution in prolonged cold preservation of kidney allografts. Transplantation 2006; 81: 480-482.

13. de Boer J, Smits JMA, De Meester J et al. A randomized multicenter study on kidney preservation comparing HTK and UW. Transplant Proc 1999; 31: 2065-2066.

14. Trushkov S, Bicans J, Shevelev V, Jushinskis J, Suhorukov V, Rozental R. Use of HTK solution in kidney preservation. Transplant Proc 2003; 35: 766 .

15. Custodiol (HTK) prescribing information, March 2004. Available from: http://www.custodiol.ca/resources/Custodiol-InsertCdn-English.pdf. Accessed October 13, 2007.

16. Salahudeen AK, Haider N, May W. Cold ischemia and the reduced long-term survival of cadaveric renal allografts. Kidney Int 2004; 65: 713-718.

17. Locke JE, Segev DL, Warren DS, Dominici F, Simpkins CE, Montgomery RA. Outcomes of kidneys from donors after cardiac death: Implications for allocation and preservation. Am J Transplant 2007: 7: 1797-1807.

18. Englesbe MJ, Punch JD, Armstrong DR, Arenas JD, Sung RS, Magee JC. Single-center study of technical graft loss in 714 consecutive renal transplants. Transplantation 2004; 78: 623-626. 